\title{
Análise dos riscos de erosão costeira em uma praia localizada no Nordeste do estado do Pará
}

Processos erosivos em Zonas Costeiras têm ocorrido de forma mais intensa devido às pressões originadas de atividades antrópicas nessas áreas, sendo decorrentes do processo histórico de uso e ocupação do solo e de atividades como o turismo não sustentável. Nesse contexto, o presente estudo teve como objetivo realizar um diagnóstico da percepção ambiental relacionada aos riscos da erosão costeira pelos frequentadores da praia do Maçarico, em Salinópolis/PA. Para isso, fo realizada uma pesquisa de caráter quali-quantitativo, na qual se utilizou questionários com perguntas fechadas de múltipla escolha, possibilitando caracterizar o perfil socioeconômico dos entrevistados, as formas de utilização da praia e a percepção com relação à erosão costeira. Os resultados demonstraram que os usuários são, em sua maioria, moradores do município e já frequentam a praia há mais de dez anos, além disso, muitos reconhecem que existe um processo de erosão costeira em estado avançado e percebem os riscos do avanço do mar no agravamento da erosão (mesmo sendo um processo natural) que, no entanto, é acelerada por outras causas como a construção de prédios próximos a praia, as ações antrópicas e as mudanças climáticas que atualmente é um fenômeno sentido a nível mundial. Diante disso, é necessário a implementação de um gerenciamento costeiro dessa praia pelo poder público e dado o cenário, medidas de conscientização ambiental são essenciais para a compreensão da dinâmica espacial da paisagem e conservação da Praia do Maçarico.

Palavras-chave: Turismo; Ocupação do Solo; Avanço do Mar.

\section{Analysis of the risks of coastal erosion on a beach located in the Northeast of Pará state}

\begin{abstract}
Erosive processes in Coastal Zones have been occurring more intensely due to the pressures arising from human activities in these areas, resulting from the historical process of land use and occupation and activities such as unsustainable tourism. In this context, the present study aimed to make a diagnosis about the environmental perception related to the risks of coastal erosion by the visitors of Maçarico beach, in Salinópolis/PA. For this, a qualitative and quantitative research study was conducted in which questionnaires with multiple choice closed questions were used, making it possible to characterize the socioeconomic profile of the interviewees, the ways of using the beach and the perception regarding coastal erosion. The results showed that the majority of users are residents of the municipality and have frequented the beach for more than ten years, in addition, many recognize that there is a process of coastal erosion in an advanced state and perceive the risks of the advancing sea in the worsening of erosion (even though it is a natural process) which, however, is accelerated by other causes such as the construction of buildings close to the beach, human actions and climate change that is currently a phenomenon felt worldwide. Therefore, it is necessary to implement a coastal management of this beach by the government and, due to the scenario, environmental awareness measures are essential for understanding the spatial dynamics of the landscape and conservation of Maçarico beach.
\end{abstract}

Keywords: Tourism; Land occupation; Sea advance.

Topic: Uso Sustentável da Biodiversidade

Reviewed anonymously in the process of blind peer.
Received: 05/12/2020

Approved: 20/02/2021
Cézar Di Paula da Silva Pinheiro (iD

Instituto Tecnológico Vale, Brasil

http://lattes.cnpq.br/9477837707374728

http://orcid.org/0000-0003-3946-2379

cezarpinheiroo@hotmail.com

Ivana Cristina Correa Sarmento (iD

Universidade Federal Rural da Amazônia, Brasil

http://lattes.cnpq.br/2699197871099942

http://orcid.org/0000-0002-6548-0362

cezarpinheiroo@hotmail.com

Douglas Silva dos Santos

Universidade Federal Rural da Amazônia, Brasil

http://lattes.cnpq.br/7130358827742214

http://orcid.org/0000-0001-7195-0685

cezarpinheiroo@hotmail.com

\section{Referencing this:}

PINHEIRO, C. P. S.; SARMENTO, I. C. C.; SANTOS, D. S.. Análise dos riscos de erosão costeira em uma praia localizada no Nordeste do estado do Pará. Nature and Conservation, v.14, n.1, p.62-70, 2021. DOI: http://doi.org/10.6008/CBPC2318-2881.2021.001.0007 


\section{INTRODUÇÃO}

A gestão costeira integrada, que pode ser definida como um processo continuo e dinâmico através do qual são realizadas decisões e ações voltadas para o desenvolvimento, uso sustentável e proteção das áreas costeiras e demais recursos do ambiente marinho (CICIN-SAIN et al., 1998; ASMUS et al., 2006), tornase de grande importância frente a crescente necessidade em se administrar, de forma ambientalmente sustentável, os recursos ambientais da Zona Costeira (ZC), conhecida como uma das regiões mais ameaçadas do planeta por conta de suas inúmeras importâncias sociais e econômicas (atrativo comercial, industrial, turístico etc.) como também ambientais (proteção contra a erosão causada por inúmeros agentes oceanográficos, fluviais e meteorológicos) (ASMUS et al., 2006; HALPERN et al., 2012; MEDEIROS et al., 2014; RAO et al., 2015; RANIERI et al.; 2016).

Nesse sentido, de acordo com Brindeiro et al. (2018), as intervenções antrópicas ocorridas nas ZCs (intimamente relacionadas à crescente demanda turística e econômica), vêm contribuindo de forma significativa para o avanço dos processos erosivos nas praias arenosas, conferindo, assim, uma maior vulnerabilidade relacionada aos riscos de erosão para as pessoas que moram nessas áreas (PEREIRA et al., 2013; SENHORAS, 2019).

Assim, o espaço litorâneo do Estado do Pará, inserido na denominada Zona Costeira Amazônica Brasileira (SILVA et al., 2017), vem se destacando como exemplo de uso e ocupação do solo de forma não planejada no Norte do País. Entre o conjunto de municípios destaca-se o de Salinópolis, localizado no Nordeste Paraense, onde o processo de ocupação é resultado direto da atuação de atores sociais que advém do período colonial (SOUZA et al., 2016). Ranieri et al. (2016) e Pinheiro et al. (2020a) afirmam que, a erosão nas principais praias deste município vem acarretando em diversos impactos ambientais negativos, tal como o recuo de barracas e perda parcial de moradias, além disso, também há casos de comprometimento de algumas das principais vias de acesso as praias, entre as quais, a da Praia do Maçarico, locus desta pesquisa.

As ações voltadas para o planejamento e gestão ambiental devem considerar o conhecimento prévio no que diz respeito as relações pré-existentes entre a sociedade e a natureza, de modo a viabilizar a solução de possíveis conflitos e, consequentemente, os resultados dos planos de gestão (PAULA et al., 2014). Dessa forma, a análise da percepção ambiental apresenta-se como uma ferramenta de grande importância para o conhecimento das relações entre homem-ambiente, podendo apontar a impressão ou juízo intuitivo sobre a natureza e a magnitude de um determinado risco com base no conjunto de conhecimentos que o indivíduo acumulou durante o seu desenvolvimento cultural, auxiliando assim para o planejamento e gerenciamento das praias (BRINDEIRO et al., 2018; MARIN, 2008; MORAIS, 2018; FERNANDES et al., 2013). Nesse cenário, a presente pesquisa tem como objetivo realizar um diagnóstico da percepção ambiental relacionada aos riscos da erosão costeira pelos frequentadores da praia do Maçarico, em Salinópolis/PA. 


\section{MATERIAIS E MÉTODOS}

\section{Caracterização da área de estudo}

A pesquisa foi realizada no município de Salinópolis, situada na Mesorregião Nordeste do estado do Pará e costa atlântica da Amazônia Brasileira, tendo como área de estudo a Praia do Maçarico (Figura 1). O município da pesquisa está situado a 220 km de Belém, capital do Estado, por via terrestre, cujo acesso se dá principalmente através da Rodovia BR-316 e da PA-124 (RIBON et al., 2017). De acordo com o último censo realizado pelo Instituto Brasileiro de Geografia e Estatística (IBGE) a população era de 37.421 habitantes, no entanto, estima-se que em 2019 tenha-se alcançado aproximadamente 40.675 pessoas.

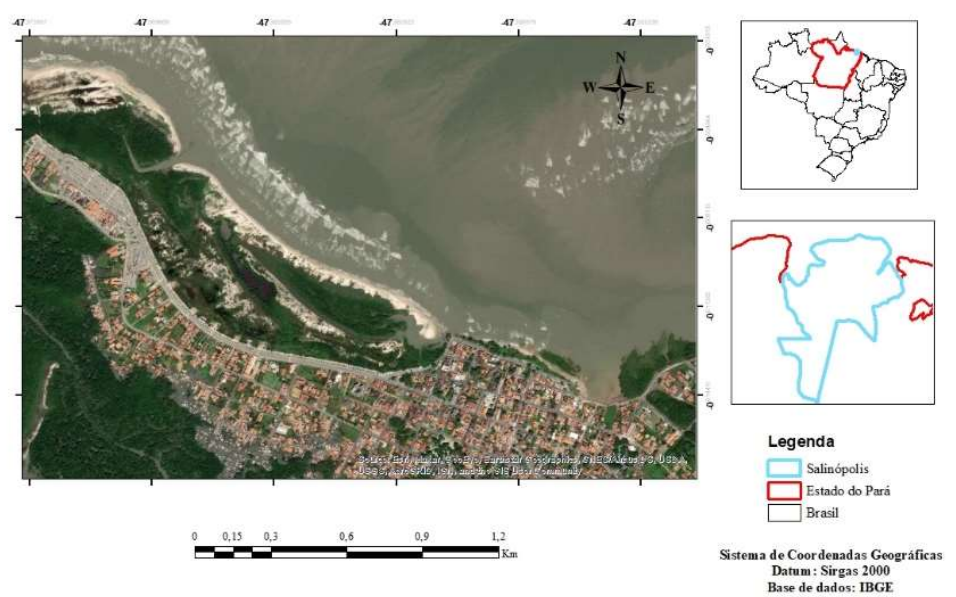

Figura 1: Localização da área de estudo.

Devido à proximidade com a foz do Rio Sampaio, a praia do Maçarico é (das praias do município) a menos exposta ao oceano aberto, além disso, conecta-se diretamente à praia da Corvina, sendo limitada pela Orla do Maçarico por falésias da Formação Barreira, dunas e restinga (RANIERI et al., 2016). Com “[...] características de praia oceânica, com declives suaves a médios, ondas deslizantes, granulometria grossa a muito fina" (RANIERI, 2014). No trecho é possível observar um grande número de ambientes construídos, com a existência de residências, hotéis, bares e restaurantes.

\section{Metodologia de trabalho}

A coleta de informações foi realizada através da revisão de literatura em periódicos, endereços eletrônicos e pesquisa documental. O levantamento de dados para a pesquisa em campo se deu através de entrevistas semiestruturadas, a partir de uma adaptação dos modelos de questionários propostos por Medeiros et al. (2014) e Brindeiro et al. (2018), com metodologia da pesquisa de caráter quali-quantitativo, que de acordo com Marconi et al. (2004), consiste no delineamento ou análise empírica de fatos ou fenômenos.

Assim, foram aplicados 25 questionários, contendo 18 perguntas de múltipla escolha, as quais foram distribuídas em três categorias: (1) perfil socioeconômico dos entrevistados, (2) formas de utilização da praia e (3) percepção em relação ao avanço da erosão costeira. A escolha dos respondentes se deu de forma 
aleatória, onde a aplicação ocorreu na área correspondente à faixa de praia e no calçadão acima da faixa de areia durante o primeiro semestre de 2019.

Posteriormente, os dados coletados foram tabulados, armazenados e submetidos à análise estatística por meio do software Statistical Package for the Social Science (SPSS) para Windows, versão 22.0.

\section{RESULTADOS E DISCUSSÃO}

Com o intuito de caracterizar o público-alvo da pesquisa, procurou-se inicialmente conhecer o perfil socioeconômico dos entrevistados, os resultados podem ser observados a seguir (Figura 2).

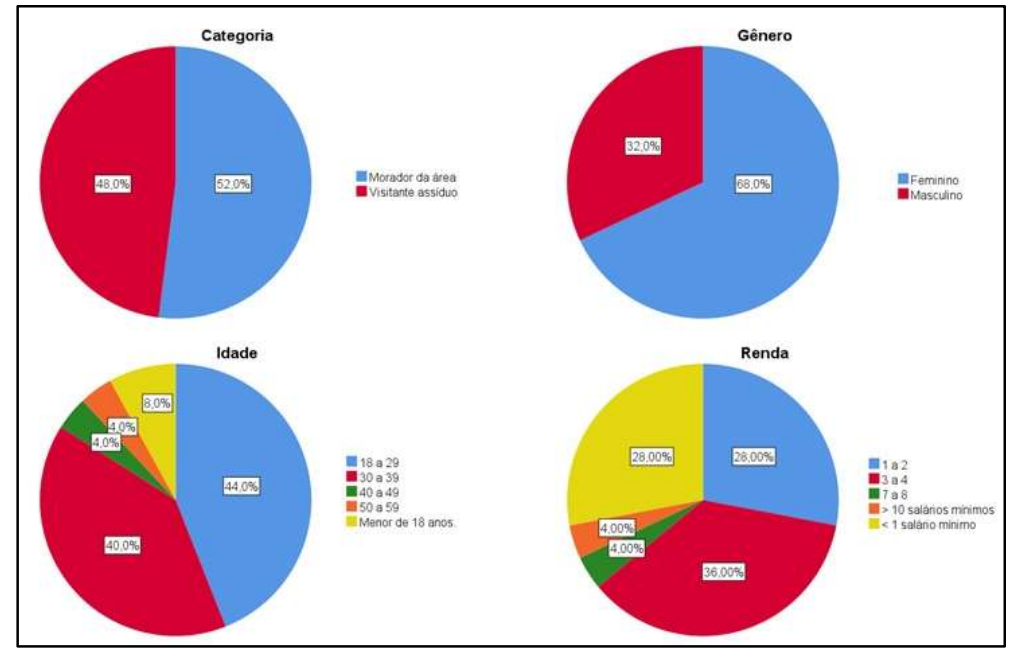

Figura 2: Perfil socioeconomico dos entrevistados.

A partir dos resultados obtidos, percebeu-se que o perfil dos entrevistados foi formado principalmente por moradores da área, com 52\%. Em relação ao gênero, o sexo feminino representou a grande maioria, 68\%. Quanto à faixa etária, a maioria dos entrevistados, 44\%, possuem idades entre 18 a 29 anos. Sobre a renda familiar, a maioria afirmou possuir uma renda média situada entre 3 a 4 salários mínimos, $36 \%$.

Após isso, perguntou-se aos entrevistados sobre a frequência com que frequentavam a praia, onde 76\% afirmaram visitarem a área a mais de 10 anos. Esse alto percentual, segundo Choudri et al. (2016), é um fator de grande importância uma vez que, por visitarem com frequência o local de estudo, os entrevistados tendem a possuir uma maior percepção a respeito das transformações ocorridas no ambiente.

Em relação ao principal atrativo da praia segundo os usuários, as opções referentes à questão paisagística e a tranquilidade do local obtiveram as maiores porcentagens, 31,7\% cada, seguidos por $23,3 \%$ que apontaram práticas de lazer, $10 \%$ a balneabilidade, e as opções de infraestrutura e práticas de esporte $1,7 \%$ cada (Figura 3 ).

Os elementos paisagísticos de Salinópolis são bastante vastos, composto principalmente por praias, rios, furos, restingas, mangues e dunas (GUTIERREZ et al., 2017). A praia do Maçarico é um dos pontos mais frequentados no município, na orla da praia encontra-se um vasto número de restaurantes e bares, assim como hotéis e alojamentos que dividem cenário com mangues, palmeiras, areia branca e demais paisagens naturais. 
Quando indagados sobre os principais problemas existentes na praia, a maioria dos entrevistados, 29\%, apontaram a erosão como principal problemática, confirmando, desse modo, a sensibilidade da área em função dos problemas erosivos, enquanto isso 19,4\% afirmaram ser a poluição, 16,1\% avanço do mar, 12,9\% violência urbana, 11,3\% acessibilidade, 9,7\% infraestrutura e 1,6\% outros problemas relacionados principalmente a questão paisagística (Figura 4).

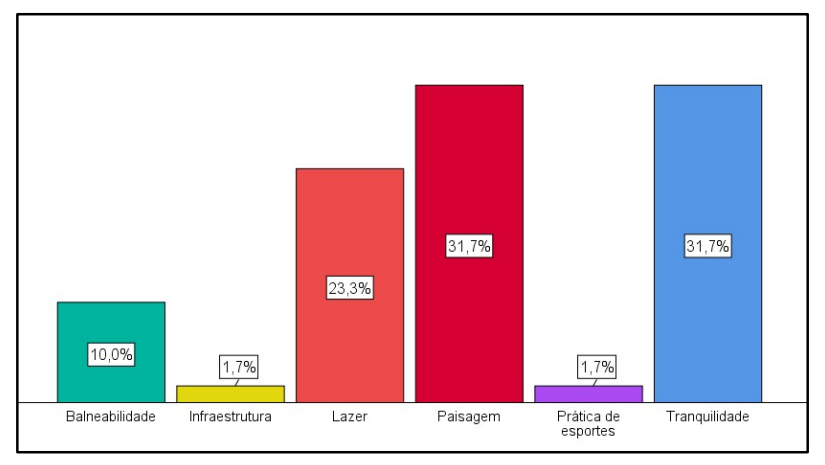

Figura 3: Principais atrativos da praia do Maçarico segundo os entrevistados.

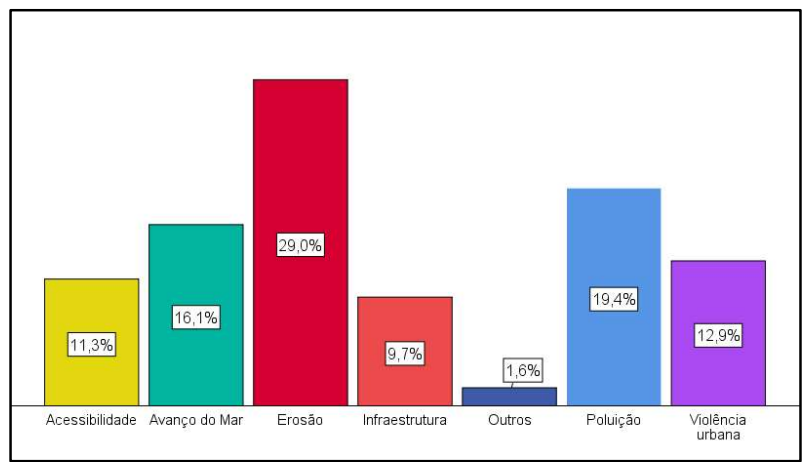

Figura 4: Principais problemáticas encontradas na praia do Maçarico segundo os entrevistados.

Na praia do Maçarico, a erosão vem causando sérios prejuízos e impactos ambientais relacionados principalmente ao turismo, por conta da destruição da infraestrutura turística, o que acarreta em vários prejuízos econômicos, uma vez que o fenômeno da depreciação da paisagem acaba afastando os frequentadores da praia, ocasionando inúmeros danos aos comerciantes locais e comprometendo a qualidade ambiental da praia (RANIERI et al., 2016; PINHEIRO et al., 2020a).

A partir de estudo realizado por Pinheiro et al. (2020b) a respeito da percepção da população de Salinópolis sobre os principais problemas ambientais no município, foi possível identificar que 84,03\% dos moradores entrevistados perceberam algum tipo de problemática ambiental no município, incluindo aquelas associadas a poluição das praias e processos erosivos, o que colabora para alertar sobre a necessidade de se atentar a tais aspectos.

Dando continuidade, ao serem perguntados como classificariam o risco do avanço do mar no processo erosivo da praia (de acordo com uma escala de intensidade variando de inexistente a alto), $48 \%$ responderam como alto (Figura 5).

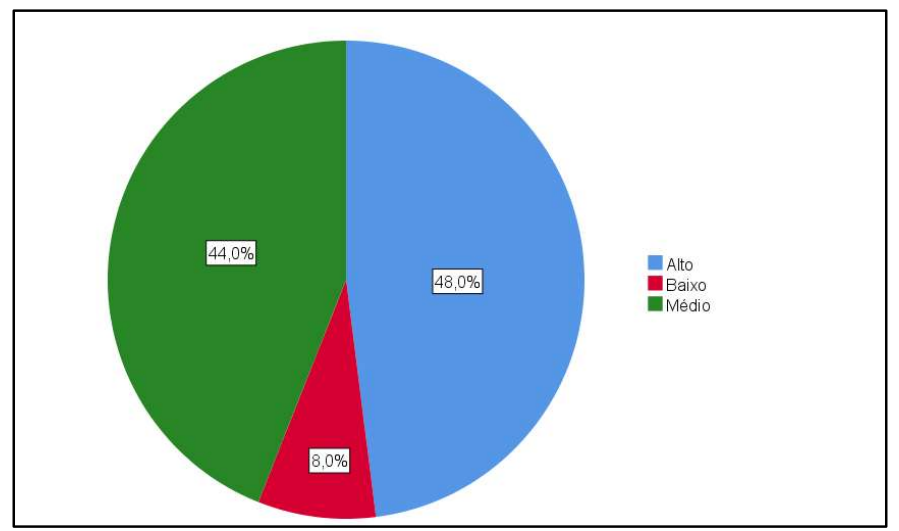

Figura 5: Classificação do risco do avanço do mar no processo erosivo da praia do Maçarico segundo os entrevistados. O resultado demonstra que os usuários possuem certo conhecimento sobre os riscos ocasionados 
pelo avanço do mar e consequente erosão da zona costeira da praia. Além disso, ao serem indagados sobre o grau de importância no controle do avanço do mar, a grande maioria, 92\%, afirmaram ser muito importante.

Assim, durante caminhada ao longo da praia do Maçarico, foi possível averiguar a existência de diversos pontos de erosão costeira, tendo como maior consequência a destruição de ambientes construídos, tal como parte da estrutura de proteção da praia, contribuindo, dessa forma, para a presença de restos de bloco de concreto espalhados ao longo da faixa de praia (Figura 6).

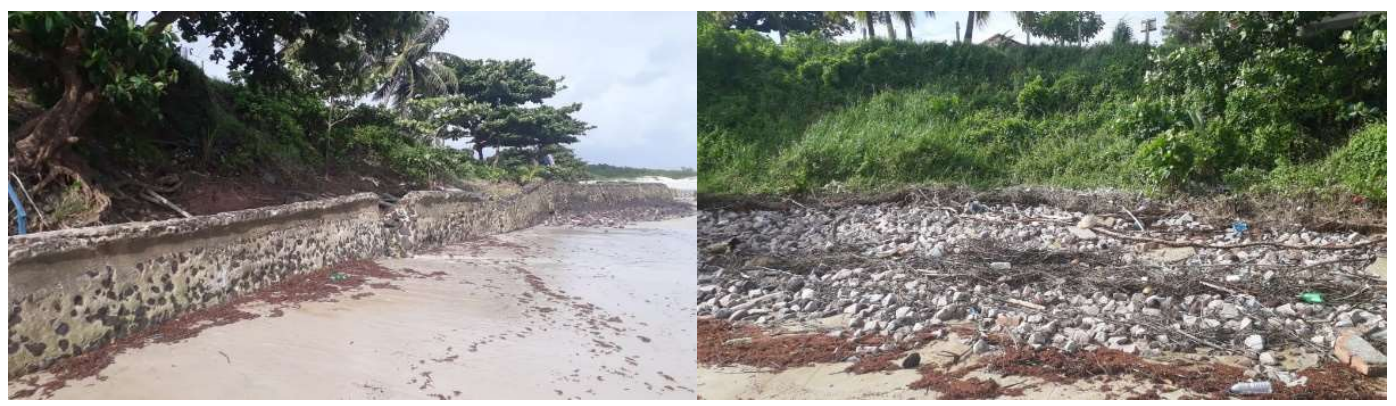

Figura 6: Erosão costeira encontrada na praia do Maçarico.

Tal problemática também foi observada por Pinheiro et al. (2020b). De acordo com Souza et al. (2005) e Souza (2009a), entre os impactos ambientais negativos acarretados pela erosão costeira, nos âmbitos sociais e ambientais, tem-se: a redução na largura da praia/linha de costa; o desaparecimento da área conhecida como pós-praia, região fora do alcance das ondas e mares normais; a perda/desequilíbrio de habitats como as dunas e manguezais; o aumento na frequência e magnitude de inundações na ZC; perda de bens e propriedades; perda paisagística; comprometimento turístico; gastos acarretados por eventuais perdas e na recuperação de praias e suas infraestruturas; e perda dos serviços ecossistêmicos (RAO et al., 2015).

Medeiros et al. (2014) afirmam que o avanço do mar é um fenômeno global, que não ocorre de maneira localizada e que já vem sendo registrado ao longo do litoral brasileiro, com efeitos diferenciados de região para região, sendo um dos fatores para que as áreas costeiras sejam consideradas como de risco.

Posteriormente, perguntou-se aos usuários sobre o nível de interferência do avanço da erosão costeira nas atividades de lazer desenvolvidas na área, onde $48 \%$ responderam serem muito afetadas, $36 \%$ razoavelmente afetadas, $12 \%$ afirmaram não haver interferência e $4 \%$ pouco afetadas. Quando indagados a respeito da intervenção da erosão nas atividades dos comerciantes locais, $60 \%$ reconheceram que a mesma é prejudicada a todo o momento, 32\% alegaram às vezes e $8 \%$ nunca (Figura 7).

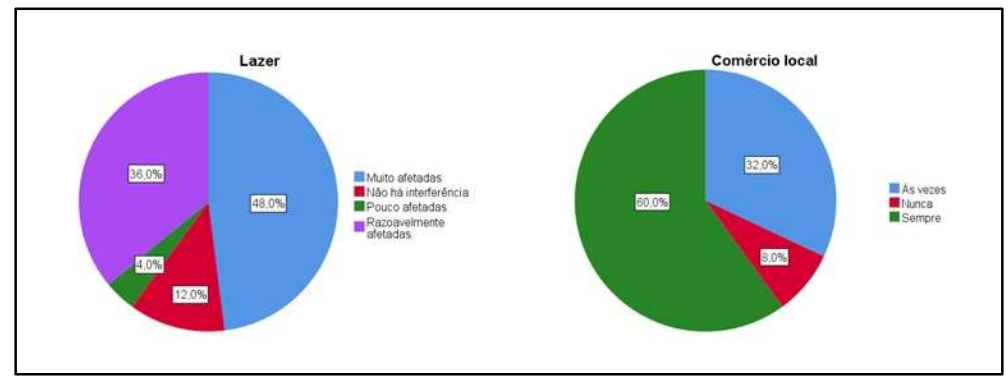

Figura 7: Nível de interferência da erosão nas atividades de lazer e comércio local segundo os entrevistados. 
Segundo Freitas (2015) o turismo é uma das principais atividades econômicas de diversas cidades costeiras. Quando realizado de forma sustentável (levando-se em consideração os aspectos sociais, ambientais e econômicos), o mesmo é capaz de trazer várias melhorias nas condições econômicas, na promoção social e cultural e até mesmo na proteção dos recursos ambientais. Dessa forma, os transtornos causados pela erosão, no sentido de impossibilitar ou acarretar em alterações nas atividades realizadas nas ZCs, pode ser refletida diretamente na economia da região, uma vez que atinge diretamente as atividades realizadas no local.

Ao serem questionados sobre os fatores responsáveis pelo avanço da erosão na praia, as respostas variaram bastante, $29,8 \%$ associaram a mesma as construções próximas à praia, 27,7\% as ações antrópicas e $25,5 \%$ as mudanças climáticas, as opções referentes ao barramento de areia ou dunas e outras causas obtiveram $8,5 \%$ cada (Figura 8 ).

Salinópolis vem passando por uma intensa transformação e crescimento urbano (SOUZA, 2014), onde, a "construção de segundas residências nas regiões estuarinas, consequência da exploração imobiliária desordenada e, muitas vezes, ilegal, é a principal responsável pela configuração espacial das construções, incluindo as transformações e as degradações paisagísticas [...]" (PINHEIRO et al., 2020b).

Os resultados encontrados na Figura 8 corroboram com estudo realizado por Medeiros et al. (2014) em uma praia turística no nordeste brasileiro, onde mais de $80 \%$ dos entrevistados acreditam que as ações de origem humana na região são as principais causadoras da erosão local.

Para Souza (2014), a urbanização provinda do turismo desordenado, através da implantação de grandes equipamentos de lazer, tem provocado alterações no meio ambiente natural e até mesmo na comunidade local. Visto que muitos dos equipamentos construídos não levam em consideração os aspectos sociais e ambientais. De acordo com a autora, as ações de empresas e do próprio Estado aceleram o processo de exploração imobiliária e supervalorização do solo litorâneo por meio da construção de hotéis, estradas e infraestruturas que nem sempre estão de acordo com as normas e as leis ambientais.

Em seguida, procurou-se saber se, na percepção dos entrevistados, os órgãos públicos (prefeitura/secretarias) demonstram preocupação com a questão do avanço da erosão na praia, 52\% dos pesquisados apontaram como sendo pouca, $44 \%$ nenhuma e apenas $4 \%$ bastante. Além disso, buscou-se saber se existe por parte do corpo de bombeiros ou defesa civil alguma medida protetiva para evitar acidentes ou deslizamentos, onde $60 \%$ responderam que sim, porém a mesma seria apenas parcial.

Em acordo com Souza (2009b),

[...] as políticas de planejamento e ordenamento territorial pouco têm incorporado os conhecimentos científicos disponíveis sobre o tema, resultando, muitas vezes, no desperdício de recursos públicos com obras de engenharia costeira que acabam não cumprindo seu papel, mas acelerando a erosão e aumentando as situações de risco e a vulnerabilidade de pessoas e bens ao processo. (SOUZA, 2009b)

Para finalizar, indagou-se sobre quais ações os usuários da praia consideram como as mais importantes para melhorar a atual situação do Maçarico, onde foram apresentados uma série de opções relacionadas aos problemas levantados. As três escolhas que obtiveram as maiores porcentagens estavam relacionadas com a melhoria da conservação ambiental da praia, através de atividades de educação 
ambiental e limpeza, 75\%, melhoria no gerenciamento costeiro contra a erosão, 18,8\%, e melhoria na segurança, com maior quantidade de policiais e guarda-vidas, 6,3\% (Figura 9).

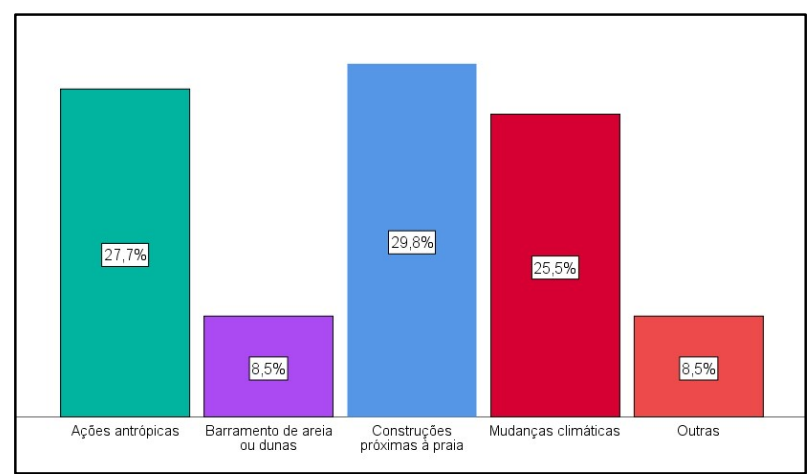

Figura 8: Fatores responsáveis pelo avanço da erosão na praia do Maçarico.

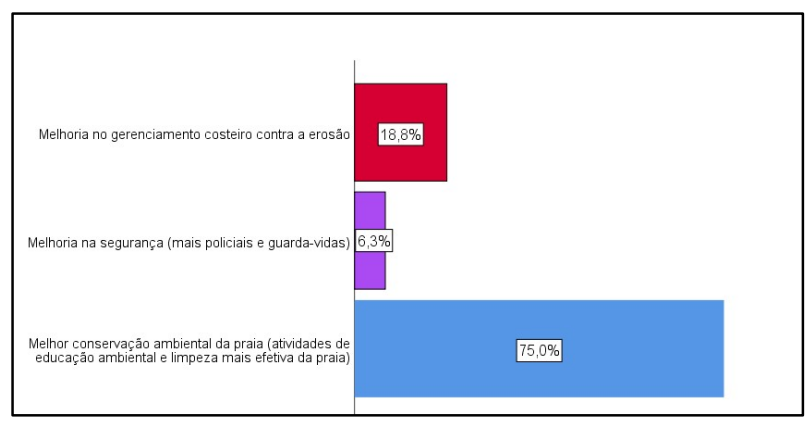

Figura 9: Ações consideradas como mais importantes para melhorar a experiência dos usuários com relação aos problemas encontrados na praia do Maçarico.

Nesse sentido, a educação ambiental, juntamente com demais ações de gestão ambiental e costeira, assumem papel estratégico para o gerenciamento costeiro, proporcionando condições para que os grupos sociais mais afetados e muitas vezes com dificuldades de participação ativa nos processos decisórios, possam compreender a problemática em sua complexidade (SILVA et al., 2017). Dessa forma, fica evidente a importância da gestão no contexto costeiro, uma vez que a mesma se torna essencial, tanto no que diz respeito a proteção e conservação ambiental, como para a melhoria da segurança e qualidade de vida da sociedade como um todo.

\section{CONCLUSÕES}

A análise da percepção ambiental dos frequentadores da Praia do Maçarico tem importância fundamental para a compreensão da realidade e dinâmica local, incluindo no que diz respeito a problemática da erosão costeira, que há anos vem causando uma série de alterações na paisagem do local.

Nesse sentido, evidenciou-se que a percepção ambiental se torna essencial para orientar ações voltadas para o turismo sustentável, gerenciamento costeiro e planejamento urbano, as quais devem ser priorizadas pelas gestões públicas como forma de conter os processos erosivos que ocorrem na praia. Assim, é de suma importância a elaboração de práticas efetivas de gestão ambiental voltadas para a zona costeira como forma de preservar o meio ambiente local, assim como o atendimento das demandas dos usuários que convivem diariamente com as problemáticas identificadas.

\section{REFERÊNCIAS}

ASMUS, M.; KITZMANN, D.; LAYDNER, C.; TAGLIANI, C. R. A.. Gestão Costeira no Brasil: Instrumentos, Fragilidades e Potencialidades. Gestão Costeira Integrada, Itajaí, v.5, p.5257, 2004.

BRINDEIRO, F. O. S.; MORAIS, J. O.. Percepção Ambiental em Relação ao Avanço do Mar na Praia do Balbino - Cascavel, Ceará, Brasil. Revista Meio Ambiente e Sustentabilidade, Curitiba, v.14, n.7, 2018. DOI: https://doi.org/10.22292/mas.v14i7.817

CHOUDRI, B. S.; BAAWAIN, M.; AL-SIDAIRI, A.; AL-NADABI, H.; AL-ZEIDI, K.. A study of beach use and perceptions of people towards better management in Oman. Indian Journal of Geo-Marine Sciences, v.45, n.9, 2016.

CICIN-SAIN, B.; KNECHT, R. W.. Integrated coastal and ocean management: concepts and practices. Washington: Island 
Press, 1998.

FERNANDES, L. G.; SANSOLO, D. G.. Percepção ambiental dos moradores da cidade de São Vicente sobre os resíduos sólidos na Praia do Gonzaguinha, SP, Brasil. Revista da Gestão Costeira Integrada, Lisboa, v.13, n.3, p.379-389, 2013. DOI: https://doi.org/10.34117/bjdv6n6-085

FREITAS, M.. Zona costeira brasileira: delimitação, questões jurídicas, unidades de conservação e natureza de patrimônio nacional. Revista de Doutrina da 4ạ Região, Porto Alegre, n.66, 2015.

GUTIERREZ, C. B. B.; GUTIERREZ, D. M. G.; SANTOS, L. S.; DIAS, N. M.; RIBEIRO, H. M. C.; MORALES, G. P.. Disposição a pagar pelo uso e conservação de um lago no cenário Amazônico: o caso do lago da Coca-Cola, Salinópolis - Pará. Espacios, Caracas, v.37, p.28-38, 2017.

HALPERN, B. S.; LONGO, C.; HARDY, D.; MCLEOD, K. L.; SAMHOURI, J. F.; KATONA, S. K.; KLEISNER, K.; LESTER, S. E.; O'LEARY, J.; RANELLETTI, M.; ROSENBERG, A. A.; SCARBOROUGH, C.; SELIG, E. R.; BEST, B. D.; BRUMBAUGH, D. R.; CHAPIN, F. S.; CROWDER, L. B.; DALY, K. L.; DONEY, S. C.; ELFES, C.; FOGARTY, M. J.; GAINES, S. D.; JACOBSEN, K. I.; KARRER, L. B.; LESLIE, H. M.; NEELEY, E.; PAULY, D.; POLASKY, S.; RIS, B.; ST MARTIN, K.; STONE, G. S.; SUMAILA, U. R.; ZELLER, D.. An index to assess the health and benefits of the global ocean. Nature, v.488, p.615-620, 2012. DOI: https://doi.org/10.1038/nature11397

MARIN, A. A.. Pesquisa em educação ambiental e percepção ambiental. Pesquisa em Educação Ambiental, v.3, n.1, p.203-222, 2008. DOI: https://doi.org/10.18675/2177580X.vol3.n1.p203-222

MARCONI, M. D. A.; LAKATOS, E. M.. Metodologia científica. 4 ed. São Paulo: Atlas, 2004

MEDEIROS, E. C. S.; PANTALENA, A. F.; MIOLA, B.; LIMA, R. S.; SOARES, M. O.. Percepção ambiental da erosão costeira em uma praia no litoral do Nordeste do Brasil (Praia da Taíba, CE). Revista de Gestão Costeira Integrada, v.14, n.3, p.471-482, 2014. DOI: http://dx.doi.org/10.5894/rgci488

PAULA, E. M. S. D.; SILVA, E. V. D.; GORAYEB, A.. Percepção ambiental e dinâmica geoecológica: premissas para o planejamento e gestão ambiental. Sociedade \& Natureza, v.26, n.3, p.511-518, 2014. DOI: http://dx.doi.org/10.1590/1982-451320140309

PEREIRA, C.; COELHO, C.. Mapas de risco das zonas costeiras por efeito da ação energética do mar. Revista de Gestão Costeira Integrada, v.13, n.1, p.27-43, 2013. DOI: http://doi.org/10.5894/rgci325

PINHEIRO, C. P. S.; ROSA, A. G.; SOUZA, A. M. L. Análise dos impactos socioambientais na zona costeira do município de Salinópolis/PA. DRd - Desenvolvimento Regional em

Debate, v.10, p.222-244, 2020a. DOI: https://doi.org/10.24302/drd.v10i0.2553

PINHEIRO, C. P. S.; SOUSA, M. C.; DIAS, R. R. C.; ROSA, A. G.; SOUSA, A. M. L.. Percepção da população, frente à mudança da paisagem e aos efeitos do turismo em áreas protegidas de Salinópolis/PA. In: SILVA JUNIOR, O. M.; PAIVA, P. F. P. R.. Áreas Protegidas: Diferentes Abordagens na Amazônia Legal. Belém: UFPA, 2020b. p.1-322.

RAO, N. S.; GHERMANDI, A.; PORTELA, R.; WANG, X.. Global values of coastal ecosystem services: A spatial economic analysis of shoreline protection values. Ecosystem services, v.11, p.95-105, 2015. DOI: https://doi.org/10.1016/j.ecoser.2014.11.011

RANIERI, L. A.. Morfodinâmica costeira e o uso da orla oceânica de Salinópolis (Nordeste do Pará). Tese (Doutorado em Geologia e Geoquímica) - Instituto de Geociências, Universidade Federal do Pará, Belém, 2014.

RANIERI, L. A.; EL-ROBRINI, M.. Condição oceanográfica, uso e ocupação da Costa de Salinópolis (Setor Corvina - Atalaia), Nordeste do Pará, Brasil. Revista de Gestão Costeira Integrada, v.16, n.2, p.133-146. 2016. DOI: http://dx.doi.org/10.5894/rgci565

RIBON, H. C.; SOUZA, I. C. M.; SILVA, I. M.; PFEIFF, G. K.. Turismo como potencial para a promoção do desenvolvimento local e sustentável no Atalaia, em Salinópolis/PA. Revista Grifos, n.43, p.96-124. 2017. DOI: http://dx.doi.org/10.22295/grifos.v26i43.3872

SENHORAS, E. M.. A gestão ambiental e sustentável na Amazônia. Ponta Grossa: Atena, 2019.

SILVA, E. P.; KITZMANN, D. I. S.; WALTER, T.; ANELLO, L. F. S.; PEREIRA, M. O. R.; GRELLERT, A. P.. Educação ambiental e gerenciamento costeiro integrado: o caso da rede regional de comercialização solidária do pescado no sul do RS. Educação Ambiental em Ação, v.60, p.2760, 2017.

SOUZA, C. D. G.; SOUZA FILHO, P. W. M.; ESTEVES, L. S.; VITAL, H.; DILLENBURG, S. R.; PATCHINEELAM, S. M.; ADDAD, J. E.. Praias arenosas e erosão costeira. In: SOUZA, G. C. R.; SUGUIO, K.; SANTOS, A. M.; OLIVEIRA, P. E.. Quaternário do Brasil. Ribeirão Preto: Holos, 2005. p.130-152.

SOUZA, C. R. G.. A erosão nas praias do Estado de São Paulo: causas, consequências, indicadores de monitoramento e risco. In: BONONI, V.; SANTOS JÚNIOR, N. A.. Memórias do conselho científico da secretaria do meio ambiente: a síntese de um ano de conhecimento científico acumulado. São Paulo: Secretaria de Meio Ambiente do Estado de São Paulo, 2009a

SOUZA, C. R. G.. A erosão costeira e os desafios da gestão costeira no Brasil. Revista de Gestão Costeira Integrada, v.9, n.1, p.17-37, 2009b.

SOUZA, D. L.. Urbanização turística, políticas públicas e desenvolvimento: o caso de Salinópolis/PA. Geografia Em Questão, v.7, n.1, p.65-86, 2014.

SOUZA, G.; ROCHA, G.; VASCONCELLOS SOBRINHO, M.. O público e o privado na apropriação do espaço na zona costeira da Amazônia brasileira: o caso da Ilha do Atalaia, estado do Pará. GeoTextos, v.12, n.1, p.105-131, 2016. DOI: http://dx.doi.org/10.9771/1984-5537geo.v12i1.14607

A CBPC - Companhia Brasileira de Produção Científica (CNPJ: 11.221.422/0001-03) detém os direitos materiais desta publicação. Os direitos referem-se à publicação do trabalho em qualquer parte do mundo, incluindo os direitos às renovações, expansões e disseminações da contribuição, bem como outros direitos subsidiários. Todos os trabalhos publicados eletronicamente poderão posteriormente ser publicados em coletâneas impressas sob coordenação da Sustenere Publishing, da Companhia Brasileira de Produção Científica e seus parceiros autorizados. Os (as) autores (as) preservam os direitos autorais, mas não têm permissão para a publicação da contribuição em outro meio, impresso ou digital, em português ou em tradução. 